\title{
Results of screening in Lublin Province, Poland, for colorectal cancer and neoplastic polyps - the role of environmental factors
}

\author{
Halina Cichoż-Lach', Justyna Szumiło², Krzysztof Celiński', Beata Kasztelan-Szczerbińska',

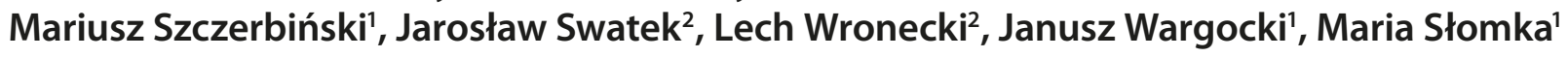 \\ ${ }^{1}$ Department of Gastroenterology, Medical University of Lublin, Poland \\ 2 Department of Clinical Pathomorphology, Medical University of Lublin, Poland
}

\begin{abstract}
Cichoż-Lach H, Szumiło J, Celiński K, Kasztelan-Szczerbińska B, Szczerbiński M, Swatek J, Wronecki L, Wargocki J, Słomka M. Results of screening in Lublin Province, Poland, for colorectal cancer and neoplastic polyps - the role of environmental factors. Ann Agric Environ Med. 2017; 24(1): 108-112. doi: 10.5604/12321966.1227648
\end{abstract}

\begin{abstract}
Introduction and objective. Screening colonoscopy is a recommended tool, and the most sensitive and cost-effective method for reducing the incidence of colorectal cancer (CRC).

Objective. The purpose of the study was to present the results of a 5-year screening for early detection of CRC carried out among the population of the central-eastern regions of Poland, primarily in Lublin Province.

Materials and method. Screening colonoscopy was conducted in a group of 1,009 patients - 636 women and 373 men, aged 40-65 years.

Results. Neoplastic polyps were found in 275 patients, advanced adenomas in 49 patients and adenocarcinoma in 13. $70.55 \%$ of neoplastic polyps was located in the distal colon, $18.9 \%$ in the proximal part and $10.55 \%$ in both regions, advanced adenomas in $79.59 \%, 8.16 \%$ and $12.25 \%$, respectively. Adenocarcinoma was located in the proximal colon in 2 cases and in the distal region in 11 cases. Neoplastic polyps and advanced adenomas occurred significantly more frequently in smokers than in non-smokers. Neoplastic polyps were found statistically more frequent in males than in females, among the overweight and obese patients, than in subjects with normal BMI, and more frequently in the group of urban, compared to rural patients. However, the frequency of advanced adenomas and CRC was not statistically different in those groups. The incidence of CRC was statistically more frequent in males than in females. Smoking and male gender were significant risk factors for developing neoplastic polyps. Male gender seemed to predispose to CRC. Obesity was found to favour advanced adenomas.

Conclusions. The results of screening found neoplastic polyps in every third person (mean) who did not have any symptoms suggestive of colon pathology. Advanced adenomas were found in 5\% of the examined and CRC was detected in $1.29 \%$ of participants. Smoking, male gender and overweight were significant risk factors for developing neoplastic polyps. No correlation was found between gender and the location of neoplastic polyps and advanced adenomas in the colon.
\end{abstract}

\section{Key words}

neoplastic polyps of colon, advanced adenoma of colon, colorectal cancer screening

\section{INTRODUCTION}

Colorectal cancer (CRC) is one of the main medical problems particularly common in highly-developed countries. It affects $1.2 \mathrm{mln}$ of the world population each year, which accounts for ca. $10 \%$ of all carcinomas. $60 \%$ of cases are noted in highly developed countries. In the EU countries, ca. 400,000 citizens contract CRC each year, which accounts for $12.9 \%$ of newly diagnosed carcinomas: $12.8 \%$ in males and $13.1 \%$ in females. About 200,000 people die of CRC, which makes CRC second to lung cancer the most deadly malignancy in the USA and EU. Globally, CRC is the cause of $12.2 \%$ of deaths from various malignancies. The incidence of CRC has risen dramatically and each year $5 \%$ of new cases are reported among people after the age of 50 . The peak of incidence occurs in the 7th-8th decade of life $[1,2]$.

Among European countries, the highest dynamics of CRC incidence is observed in Poland. The number of sufferers

Address for correspondence: Halina Cichoż-Lach, Department of Gastroenterology, Medical University of Lublin, Poland

E-mail: lach.halina@wp.pl

Received: 25 July 2013; accepted: 13 January 2014; first published on December, 2016 who die of CRC (10,500 people/year) is significantly higher compared to the rates noted in Western and Northern Europe [3]. According to EU experts, early diagnostics of CRC can lower the death rate by at the least $40 \%$. Data from the State Register of Carcinomas in Poland suggest that early endoscopic diagnostics is likely to reduce the risk of developing CRC by more than $50 \%$ in the coming decade. Screening colonoscopy, aside from such methods as repetitive faecal occult blood testing (FOBT) or flexible sigmoidoscopy (FS), is among the diagnostic protocols suggested to improve the statistics. It is a recommended tool as it is the most sensitive and cost-effective method to reduce the incidence and death rate from CRC. Its benefits include early detection and removal of pre-neoplastic polyps and less advanced asymptomatic early-stage carcinomas, and leads to an increased rate of successful treatment (5-year survival) and lowers the costs of treatment $[4,5]$. Many countries have created their own nation-wide screening programmes for the early detection of CRC, implemented by the ministries of health, and each has its own strategy and recommendations $[6,7]$. In Poland, the basic goal of the scheme is to reduce the death rate from CRC by increasing the detection rate of 
early-stage cancers (A and B stage of Dukes classification), increasing the number of CRCs cured, inhibiting the growth of new cases, and lowering the costs of treatment.

\section{OBJECTIVE}

The purpose of the study was to present the results of a 5-year screening for early detection of CRC, which is a part of a national programme carried out among the population of the central-eastern regions of Poland, primarily in the Lublin Province. The frequency and location of polyps within the large intestine, which accounts particularly for neoplastic polyps, was assessed. An additional aim was to determine the most common locations of neoplastic polyps and CRC, and to discover whether they are gender-linked. The incidence of neoplastic polyps and CRC in smokers and non-smokers, and in people with and without a family history of CRC was analyzed. Additionally, the incidence of neoplastic polyps and CRC cases with reference to BMI and the place of living (urban and rural population) was analyzed. Of particular interested, was whether gender, cigarette smoking, family history of CRC, BMI and place of residence were among the risk factors for developing CRC and neoplastic polyps.

\section{MATERIALS AND METHOD}

Screening for CRC was conducted between 2008 - 2012 among patients aged 50-65years, disregarding family history, together with individuals aged $40-65$ yrs with a family history of CRC in a first-degree relative, and those aged 25-65years with a history of genetically confirmed hereditary nonpolyposis colon cancer (HNPCC). The participants did not have symptoms suggesting of a colon pathology: without significantly altered bowel motions, no bleeding from the lower alimentary tract, no abdominal pains or unexplained weight loss. Each participant signed consent to participate in the study and responded to a questionnaire that included information about body weight and height, smoking (current smoking or history of smoking), family history of CRC, and history of surgeries. As for smoking, the cases of current smokers and ex-smokers with at least a year history of smoking more than 10 cigarettes daily were included.

The patients with contraindications or increased risk of colonoscopy (active severe cardiac disease, pulmonary disease, other serious conditions) were excluded from the study protocol. Each patient had BMI (body mass index) calculated according to the formula: body mass $(\mathrm{kg}) /$ height $(\mathrm{m})^{2}$. BMI range of $18.50-24.99 \mathrm{~kg} / \mathrm{m}^{2}$ was assumed to be normal, BMI of $25-29.99 \mathrm{~kg} / \mathrm{m}^{2}$ was considered overweight, and obesity diagnosed at $\mathrm{BMI} \geq 30 \mathrm{~kg} / \mathrm{m}^{2}$.

Colonoscopy was carried out by one of a group of four doctors. In each case, anatomical location and size of the polyp/ carcinoma was defined. The polyp size was assessed by comparison of the polyp head with opened biopsy forceps $(5 \mathrm{~mm})$, and in the case of certain peduncular polyps by directly measuring the polyp size following endoscopic polypectomy. All polyps were removed during first screening colonoscopy or on an elective basis, and histopathologically investigated. Histopathological diagnosis was performed by one of three pathologists experienced in gastrointestinal tract pathology who participated in the study. If more than one polyp was detected, the patient was classified according to the most histologically advanced lesion.

The distal colon was defined as the rectum, sigimoid, descending colon and the splenic flexure; proximal colon as the transverse colon, ascending colon and the caecum.

Neoplastic polyps were qualified on the basis of histopathological findings as adenomas and advanced adenomas. Advanced adenoma was defined as an adenoma bigger than $1 \mathrm{~cm}$ in diameter and/or with tubullo-villous or villous component and/or with high-grade dysplasia.

Inflammatory and hyperplastic polyps were not analyzed.

Urban patients were defined as coming from cities with $\geq$ 5,000 inhabitants and rural patients lived in places with less than 5,000 inhabitants.

Statistical analysis. The results were analyzed statistically by chi square test for independence, Fisher's exact test and Mann-Whitney $\mathrm{U}$ test; odds ratio (OR) and 95\% $\mathrm{Cl}$ were calculated. $\mathrm{P}$ value of less than 0.05 was considered statistically significant. All statistical calculations were made using Statistica software version 10.0.

\section{RESULTS}

Screening colonoscopy was conducted in the group of 1,009 patients - 636 women (63.03\%) and 373 men (36.97\%), aged 40-65years (mean $56.08 \pm 5.41$ years). 84 participants were aged between $40-49$ years. The characteristics of examined population is presented in Table 1 . Accessibility to the caecum was successful in $97.42 \%$ of patients. In 26 cases ( 20 females and 6 males) the caecum was not reached. Among them, in 6 patients colonic diverticula were detected.

Table 1. Characteristics of examined population

\begin{tabular}{lc}
\hline No. of examined population & 1,009 \\
\hline Gender F/M n(\%) & $636(63.03 \%) / 373(36.97 \%)$ \\
\hline Age (years) & \\
Range/Mean \pm SD & $40-65 / 56.08 \pm 5.41$ \\
\hline Family history of CRC (n/\%) & $193(19.13 \%)$ \\
\hline Smokers (n/\%) & $421(41.72 \%)$ \\
F/M n $(\%)$ & $232 /(55.10 \%) / 189(44.90 \%)$ \\
\hline BMI (kg/m $\left.{ }^{2}\right)$ & $19.23-39.09 / 27.34 \pm 4.74$ \\
Range/Mean \pm SD &
\end{tabular}

None of the participants suffered from any complications following colonoscopy.

790 participants $(78.30 \%)$ came from urban areas, whereas 219 (21.70\%) from rural areas of the central-eastern regions of Poland, primarily the Lublin Province. Family history of CRC in first degree relatives was positive in 193 participants (19.13\%): in this group, in 44 patients neoplastic polyps were found and 2 cases of CRC were detected. In the group of 421 respondents who declared smoking, 93 women reported current smoking and 139 had smoked in the past. In men, those values were 52 and 137, respectively.

In 721 of the examined respondents (71.46\%), no significant clinical pathologies of the colon were found: in 624 of cases, colonoscopy was completely negative, but in 97 patients, diverticula, mainly in the sigimoid, and in 47 patients hyperplastic polyps were revealed. Neoplastic polyps were found in 275 patients (27.25\%). In 49 patients 
(4.86\%), advanced adenomas and in 13 subjects $(1.29 \%)$ adenocarcinoma was detected.

The location of neoplastic polyps was as follow: $70.55 \%$ in the distal colon, $18.9 \%$ in the proximal parts and $10.55 \%$ in both regions. The advanced adenomas were located in $79.59 \%$, $8.16 \%$ and $12.25 \%$, respectively. No statistically significant differences in the location of neoplastic polyps and advanced adenomas was found between females and males $(\mathrm{p}=0.127$ and $\mathrm{p}=0.481$ ). The groups with a family history of CRC and without CRC running in the family were not statistically significantly different $(p=0.448$ and $p=0.416)$; the groups of smokers and non-smokers were also not statistically different $(\mathrm{p}=0.252$ and $\mathrm{p}=0.855)$. There were no statistically significant differences between the groups with normal BMI, overweight and obesity $(\mathrm{p}=0.913$ and $\mathrm{p}=0.481)$.

Adenocarcinoma was diagnosed in $9(2.41 \%)$ males and 4 $(0.63 \%)$ females. Two men had contributory family history of CRC among their first degree relatives. The histories of others were negative. Adenocarcinoma was located in the proximal colon in 2 cases and in the distal region in 11 cases. In the group of 13 patients with CRC, 8 patients admitted smoking (6 males and 2 females). In the group of smokers, in 6 patients the lesion was located in the distal colon, and in 2 patients - in the proximal colon. In that group, 6 patients had normal BMI, 5 patients were overweight and 2 had obesity.

Table 2 presents incidence of neoplastic polyps, advanced adenomas and CRC among different groups of examined subjects. Neoplastic polyps and advanced adenomas occurred significantly more frequently in smokers than in non-smokers ( $\mathrm{p}=0.044$ and $\mathrm{p}=0.022$ respectively); no such relation was found with respect to CRC. Neoplastic polyps

Table 2. Incidence of neoplastic polyps, advanced adenomas and CRCs among different groups of examined subjects

\begin{tabular}{|c|c|c|c|c|}
\hline Parameter & $\begin{array}{l}\text { No clinical } \\
\text { significant } \\
\text { lesions }\end{array}$ & $\begin{array}{l}\text { Neoplastic } \\
\text { polyps }\end{array}$ & $\begin{array}{l}\text { Advanced } \\
\text { adenomas }\end{array}$ & CRC \\
\hline Smokers/non-smokers (n) & $285 / 436$ & $\begin{array}{c}128 / 147 \\
\left.p=0.044^{*}\right)\end{array}$ & $\begin{array}{c}28 / 21 \\
\left.p=0.022^{*}\right)\end{array}$ & $\begin{array}{c}8 / 5 \\
p=0.254\end{array}$ \\
\hline Gender F/M (n/\%) & $484 / 237$ & $\begin{array}{c}148 / 127 \\
\left.p=0.0002^{*}\right)\end{array}$ & $\begin{array}{c}25 / 24 \\
p=0.095\end{array}$ & $\begin{array}{c}4 / 9 \\
\left.p=0.020^{*}\right)\end{array}$ \\
\hline $\begin{array}{l}\text { Family history of CRC/no } \\
\text { family history of } C R C(n)\end{array}$ & $147 / 574$ & $\begin{array}{c}44 / 231 \\
p=0,116\end{array}$ & $\begin{array}{c}7 / 42 \\
p=0.373\end{array}$ & $\begin{array}{c}2 / 11 \\
p=0.750\end{array}$ \\
\hline $\begin{array}{l}\text { BMI }(n) \\
\text { Normal/overweight/obesity }\end{array}$ & $255 / 315 / 151$ & $\begin{array}{l}75 / 138 / 62 \\
p=0.049 *\end{array}$ & $\begin{array}{l}13 / 20 / 16 \\
p=0.136\end{array}$ & $\begin{array}{c}6 / 5 / 2 \\
p=0.604\end{array}$ \\
\hline $\begin{array}{l}\text { BMI (n) } \\
\text { Normal/overweight+obesity }\end{array}$ & $255 / 466$ & $\begin{array}{c}75 / 200 \\
\left.p=0.015^{*}\right)\end{array}$ & $\begin{array}{c}13 / 36 \\
p=0.314\end{array}$ & $\begin{array}{c}6 / 7 \\
p=0.377\end{array}$ \\
\hline $\begin{array}{l}\text { Place of living (n) } \\
\text { Urban/rural }\end{array}$ & $548 / 173$ & $\begin{array}{c}232 / 43 \\
\left.p=0.004^{*}\right)\end{array}$ & $\begin{array}{c}37 / 12 \\
p=0.625\end{array}$ & $\begin{array}{l}10 / 3 \\
p=1\end{array}$ \\
\hline
\end{tabular}

*) statistically significant and CRCs were statistically more frequent in males $(33.96 \%$ and $2.41 \%$, respectively) than in females $(23.31 \%$ and $0.63 \%$, respectively) $(\mathrm{p}=0.0002$ and $\mathrm{p}=0.020$, respectively). However, advanced adenomas were not statistically different between gender groups, and family history of CRC did not correlate with any colonic pathologies.

Analysis of BMI effects found that neoplastic polyps were more frequent among the overweight and obese patients, than in the subjects with normal BMI, with no regard if those were analyzed individually $(\mathrm{p}=0.049)$ or together $(p=0.015)$. Neoplastic polyps were significantly more frequent in the group of urban people in comparison to rural people $(p=0.004)$; however, in those groups, the frequency of advanced adenomas and CRC was not statistically different.

The results revealed that smoking was a significant risk factor for developing neoplastic polyps and advanced adenomas (Tab. 3). Moreover, in the presented study, male gender seemed to predispose to neoplastic polyps and CRC. Other factors favouring the risk of neoplastic polyps included $\mathrm{BMI} \geq 25 \mathrm{~kg} / \mathrm{m}^{2}$ and place of residence. Obesity was found to favour advanced adenomas. No correlations between CRC and other examined parameters were found. Gender did not correlate with the location of neoplastic polyps and advanced adenomas in the proximal or distal regions of the colon $(\mathrm{OR}=0.7255 ; 95 \% \mathrm{CI}=0.4221-1.2467$; $\mathrm{p}=0.245$ and $\mathrm{OR}=0.2576 ; 95 \% \mathrm{CI}=0.0246-2.7010 ; \mathrm{p}=0.258$, respectively), with family history of $\mathrm{CRC}(\mathrm{OR}=0.6087 ; 95 \%$ $\mathrm{CI}=0.2417-1.5332 ; \mathrm{p}=0.292$ and $\mathrm{OR}=0.5726 ; 95 \% \mathrm{CI}=0.0274-$ $11.9733 ; \mathrm{p}=0.719$, respectively), with smoking $(\mathrm{OR}=1.6292$; 95\% $\mathrm{CI}=0.8824-3.0082 ; \mathrm{p}=0.119$ and $\mathrm{OR}=0.7727 ; 95 \%$ $\mathrm{CI}=0.0985-6.0607 ; \mathrm{p}=0.806$, respectively), and with BMI $(\mathrm{OR}=1.3575 ; 95 \% \mathrm{CI}=0.7289-2.5281 ; \mathrm{p}=0.335$ and $\mathrm{OR}=0.8627$; $95 \% \mathrm{CI}=0.2097-3.5503 ; \mathrm{p}=0.838$, respectively).

\section{DISCUSSION}

In Poland, the majority of CRC cases are diagnosed in a considerably advanced stage, especially in symptomatic patients. Screening colonoscopy is a highly effective diagnostic method to detect a pre-cancerous conditions in the colon and early-stage CRC.

In the majority of countries, FOBT is a first line screening diagnostic test to detect early-stage CRC; in the case of positive results, either FS or colonoscopy is recommended $[6,8,9]$. Poland is one of a few countries where colonoscopy is the preferred and recommended screening method, not preceded by any other tests [10].

Access to the caecum is an essential parameter for the quality of colonoscopy. The hitherto published guidelines

Table 3. Evaluation of potential risk factors of neoplastic polyps, advanced adenomas and CRC

\begin{tabular}{|c|c|c|c|c|c|c|c|c|c|}
\hline \multirow[t]{2}{*}{ Parameter } & \multicolumn{3}{|c|}{ Neoplastic polyps } & \multicolumn{3}{|c|}{ Advanced adenomas } & \multicolumn{3}{|c|}{ CRC } \\
\hline & OR & $95 \% \mathrm{Cl}$ & $p$ & OR & $95 \% \mathrm{Cl}$ & $p$ & OR & $95 \% \mathrm{Cl}$ & $\mathrm{p}$ \\
\hline Smokers & 1.3321 & $1.0067-1.7627$ & $\left.0.045^{*}\right)$ & 1.9463 & $1.0892-3.4778$ & $\left.0.025^{*}\right)$ & 2.2780 & $0.7400-7.0127$ & 0.151 \\
\hline Family history of CRC & 0.7438 & $0.5138-1.0766$ & 0.117 & 0.6911 & $0.3056-1.5632$ & 0.375 & 0.7663 & $0.1685-3.4859$ & 0.731 \\
\hline $\mathrm{BMI} \geq 25 \mathrm{~kg} / \mathrm{m}^{2}$ & 1.4719 & $1.0808-2.0045$ & $\left.0.014^{*}\right)$ & 1.5515 & $0.7979-3.0167$ & 0.196 & 0.5781 & $0.1927-1.7339$ & 0.328 \\
\hline Place of living - town & 1.7033 & $1.1794-2.4599$ & $\left.0.005^{*}\right)$ & 0.8466 & $0.4335-1.6532$ & 0.626 & 0.9231 & $0.2518-3.3837$ & 0.904 \\
\hline
\end{tabular}

*) statistically significant 
for colonoscopy indicate that the caecum should be reached in more than $95 \%$ cases [11]. Data from some screening centres in Poland state that access to the caecum was achieved in $92.2 \%$, which was assessed as a good result [12]. In the presented study, the caecum was reached in $97.42 \%$ cases. Such a result indicates the very good quality of colonoscopy, much higher than the standard recommended.

In this study, more women $(63.03 \%)$ than men $(36.97 \%)$ participated in the screening programme. Considering the fact that the patients participated of their own volition, or were invited by doctors, it has to be noted that women have better health awareness, and thus take better care of their health than men. This reflects a general trend in the Polish population [12].

The presented study found a high frequency of neoplastic polyps and advanced adenomas $(27.25 \%$ and $4.86 \%$, respectively) in the group of asymptomatic patients. The ratio was somewhat higher than in other studies carried out in Poland - $17.3 \%$ [12] but it was close to Italian studies [13]. CRC was detected in $1.29 \%$ of the examined subjects. In Croatian studies, CRC was noted in $0.26 \%$ patients [6]. In those studies, FOBT was the first choice test to detect early CRC, and colonoscopy was performed in $66 \%$ of the examined who tested positive on FOBT. Epidemiological data show that $50-70 \%$ of CRCs are located in the sigmoid and rectum [6]. In the current study, $84.67 \%$ of the detected CRCs were located in the distal colon. Likewise, neoplastic polyps and advanced adenomas were mainly located in the distal colon $(70.55 \%$ and $79.59 \%$, respectively).

The majority of data suggest a positive correlation between cigarette smoking and CRC. Meta-analysis that reviewed 36 studies found evidence that current and ex-smokers are at increased risk for developing CRC, and the mortality rate due to CRC is by $25 \%$ higher compared to people who never smoked [14]. Here, the number of cigarettes smoked daily, years of smoking addiction and an age at which the habit begun are really essential. A patient who smokes $>40$ cigarettes a day has a relative risk (RR) of CRC equal to 1.38, a patient who has smoked for $>40 y$ rs has an $R R=1.20$. The risk of CRC decreases statistically as the period of smoking abstinence increases. Gender is significant in that respect. Women who used to smoke or continue smoking have the risk of death from CRC by $40 \%$ higher in comparison to non-smoking women; in the case of men, the ratio is $30 \%$. This study found a correlation between smoking and neoplastic polyps, including advanced adenomas, but not with CRC. Perhaps this can be related to the relatively small number of analyzed CRC cases detected on screening colonoscopy.

Large-scale population surveys suggest that obesity is related to a $30-70 \%$ increase in CRC incidence. This is observed especially in males. In females, the correlation is weaker since female obesity is less common $[15,16]$. In Europe, CRC is detected in $10.9 \%$ males and in $2.6 \%$ overweight or obese females $\left(\mathrm{BMI}>25 \mathrm{~kg} / \mathrm{m}^{2}\right)$. In the group of obese and overweight, the estimated risk of CRC is 1.19 times greater than in the group with normal body weight (males: 1.41 , females -1.08 ). A $2 \mathrm{~kg} / \mathrm{m}^{2}$ rise in BMI makes the mean risk of CRC 7\% higher, a $2 \mathrm{~cm}$ increase in abdominal obesity (measured by waist circumference) rises CRC risk by a mean of $4 \%(2-5 \%)$. A similar trend is observed with reference to colorectal adenomas. BMI was found to be an independent risk factor for advanced colorectal adenomas [17, 18].
A significant correlation was found between BMI and CRC location. A $5 \mathrm{~kg} / \mathrm{m}^{2}$ rise in $\mathrm{BMI}$ increases the risk of colonic carcinoma in males $R R=1.30$, in females $R R=1.12$. Also, BMI correlated positively with rectal carcinoma in men, although the relationship was considerably weaker than in colonic carcinoma. No such correlation was found in women. Distribution of fatty tissue as abdominal obesity showed a strong correlation with colorectal cancer in both men and women, although the relationship was weaker in females [19]. Obesity can result in poorer CRC outcomes, favour recurrence, and increase mortality due to CRC. The primary mechanisms that could explain the relationship between obesity and CRC have not yet been clarified. However, researchers suppose that metabolic syndromes, insulin resistance, modified adipocitokine levels and molecular mediators are involved, although these mechanisms too have not been established to-date. One of the hypotheses suggests high insulin levels and insulin-related growth factors favour CRC development [20]. Recently published research has focused on the involvement of inflammatory processes, adipokines and estrogens in CRC. Obesity enhanced by inflammations is mainly arranged by increased macrophages in the fatty tissue which leads to the secretion of proinflammatory cytokines, including tumour necrotic factor alpha (TNF-alfa), monocyte chemoattractant protein-1 and interleukin-6 (IL-6) which, in turn, favours CRC. With increased obesity, the level of adiponectin decreases and adiponectin shows a positive correlation with CRC, especially in males. Moreover, smoking and family history of CRC seem to enhance that relationship $[21,22]$.

Analysis of the results obtained in the presented study revealed a correlation between $\mathrm{BMI} \geq 25 \mathrm{~kg} / \mathrm{m}^{2}$ and adenomas; however, no correlation with CRC was found. This could have resulted from the fact that only 13 cases of CRC were analyzed; therefore, there were relatively too few cases to draw definitive conclusions. The studies suggesting correlation between CRC and obesity involved a greater number of cases.

Similar to the current study, the research by BurnettHartman et al. [23] attempted to determine epidemiological correlations between many factors and colonic polyps. They found a strong correlation between polyps (both advanced adenomas and sessile serrated polyps of the colon) and gender, hormone replacement therapy and smoking. Those correlations presented various degrees of strength. The correlation between gender and advanced adenomas was stronger than between gender and early-stage adenomas; higher education level positively correlated with sessile serrated polyps, but not with other serrated polyps; postmenopausal hormone replacement therapy correlated with adenomas and obesity with serrated polyps. Those results illustrate the epidemiological heterogeniity of CRC and can help explain the carcinogenic mechanisms of CRC development [23].

Recent studies have suggested the involvement of oxidative stress in developing CRC, in addition to the environmental factors discussed above, lifestyle and dietary habits, obesity and physical activity. Moreover, it has been found that numerous genetic factors, exo- and endogenic, can modulate the ability of the intestinal epithelium to respond to metabolic damage and oxidative stress [24].

Family history of CRC was another independent factor of developing CRC. According to the statistics, ca. $20 \%$ of CRCs are related to family history, including 5\% single- 
gen cancer syndrome. Individuals with a family history of CRC have a $2.3-4.3$ times higher risk of developing CRC in comparison to those whose history is non-contributory in that respect [25]. Moreover, people with an early family history of CRC (diagnosed under the age of 50 years) are at greater risk than people with familial CRC detected at a later age. Therefore, in the case of a positive family history of CRC, early screening is recommended. Polish guidelines include the same recommendations. The presented study did not find increased risk of neoplastic polyps or CRC in patients with a positive family history. However, this can be explained by the small number of people with positive family history of CRC willing to participate in this programme and undergo screening.

Analysis of the current results found that place of residence was a significant factor for developing neoplastic polyps in the colon. However, no correlation was found with CRC or advanced adenomas. This can be explained by the fact that more urban dwellers participated in the study and that living in a town increases exposure to more environmental factors that favour the development of colonic pathologies.

\section{CONCLUSIONS}

The results of screening found neoplastic polyps in every third person (mean) who did not have any symptoms suggestive of colon pathology. Advanced adenomas were found in 5\% of the examined, and CRC was detected in 1.29\% of participants. Neoplastic polyps and CRCs were located in the distal colon and occurred more frequently in males than females. Neoplastic polyps were more common in the people with overweight and obesity, and among urban people compared to people living in the rural areas.

Smoking, male gender and overweight were significant risk factors for developing neoplastic polyps. No correlation was found between gender and the location of neoplastic polyps and advanced adenomas in the colon.

\section{REFERENCES}

1. Ferlay J, Autier P, Biniol P, Heanue M, Colombet M, Boyle P. Estimates of the cancer incidence and mortality in Europe in 2006. Ann Oncol. 2007; 18(3): 581-592.

2. Jemal A, Siegel R, Xu J, Ward E. Cancer statistics, 2010. Ca Cancer J Clin. 2010; 60(5): 277-300.

3. the State Register of Carcinomas in Poland http://onkologia.org.pl

4. Garborg K, Holme Ø, Løberg M, Kalager M, Adami HO, Bretthauer M. Current status of screening for colorectal cancer. Ann Oncol. 2013; 24(8): 1963-1972.

5. Young PE, Womeldorph CM. Colonoscopy for colorectal cancer screening. J Cancer. 2013; 4(3): 217-226.
6. Katicic M, Antoljak N, Kujundżic M, Stamenic W, Stoko-Poljak D, et al. Results of National Colorectal Cancer Screening Program in Croatia. World J Gastroenterol. 2012; 18(32): 4300-4307.

7. Zavoral M, Suchanek S, Zavada F, Dusek L, Muzik J, Seifert B, et al. Colorectal cancer screening in Europe. World J Gastroenterol. 2009; 15(47): 5907-5915.

8. West NJ, Boustiere C, Fischbach W, Parente F, Leicester RJ. Colorectal cancer screening in Europe: differences in approach; similar barriers to overcome. Int J Colorectal Dis. 2009; 24(7): 731-740.

9. Pox C, Schmiegel W, Classen M. Current status of screening colonoscopy in Europe and in the United States. Endoscopy. 2007; 39(2): 168-173.

10. Reguła J, Rupiński M, Kraszewska E, Polkowski M, Pachlewski J, Orłowska J, et al. Colonoscopy in colorectal cancer screening for detection of advanced neoplasia. N Eng J Med. 2006; 355(18): 1863-1872.

11. Kotowski B, Kamiński MF, Rupiński M, Kraszewska E, Pachlewski L, Orłowska J, et al. Colonoscopy quality indicators in the National Colorectal Cancer Screening Program in Poland [in Polish]. Gastroenterol Klin. 2009; 1(1): 45-53.

12. Świątkowski M, Meder A, Sobczyński L, Koza J, Szamocka M, Brudny J. The screening program for the early colorectal cancer detection performer at the Gastroenterology Departament of Nicolas Copernicus Universisty in Toruń Collegium Medium in Bydgoszcz in 2000-2009. Gastroenterol Pol. 2010; 17(6): 410-415.

13. Morini S, Hassan C, Zullo A, Lorenzetti R, de Mathaeis M, Stella F, et al. Detection of colonie polyps according to insertion/withdrawal phases of colonoscopy. Int J Colorectal Dis. 2009; 24(5): 527-530.

14. Botteri E, Iodice S, Bagnardi V, Raimondi S, Lowenfels AB, Maisonneuve P. Smoking and colorectal cancer. A meta-analysis. JAMA. 2008; 300(23): 2765-2778.

15. Ning Y, Wang L, Giovannucci EL. A quantitative analysis of body mass index and colorectal cancer: findings from 56 observational studies. Obes Rev. 2010; 11(1): 19-30.

16. Aleksandrova K, Nimptsch K, Pischon T. Influence of obesity and related metabolic alterations on colorectal cancer risk. Curr Nutr Rep. 2013; 291): 1-9.

17. Hong S, Cai Q, Chen D, Zhu W, Huang W, Li Z. Abdominal obesity and the risk of colorectal adenoma: a meta-analysis of observational studies. Eur J Cancer Prev. 2012; 21(6): 523-531.

18. Yun KE, Chang Y, Jung HS, Kim CW, Kwon MJ, Park SK, et al. Impact of body mass index on the risk of colorectal adenoma in a metabolically healthy population. Cancer Res. 2013; 73(13): 4020-4027.

19. Larsson SC, Wolk A. Obesity and colon and rectal cancer risk: a metaanalysis of prospective studies. Am J Clin Nutr. 2007; 86(3): 556-565.

20. Bardou M, Barkun AN, Martel M. Obesity and colorectal cancer. Gut. 2013; 62(6): 933-947.

21. Guffey CR, Fan D, Singh UP, Murphy EA. Linking obesity to colorectal cancer: recent insights into plausible biological mechanisms. Curr Opin Clin Nutr Metab Care. 2013 Jun 10. [Epub ahead of print]. doi: 10.1097/ MCO.0b013e328362d10b

22. An W, Bai Y, Deng SX, Gao J, Ben QW, Cai QC, et al. Adiponectin levels in patients with colorectal cancer and adenoma: a meta-analysis. Eur J Cancer Prev. 2012; 21(2): 126-33.

23. Burnett-Hartman AN, Passarelli MN, Adams SV, Upton MP, Zhu LC, Potter JD, et al. Differences in epidemiologic risk factors for colorectal adenomas and serrated polyps by lesion severity and anatomical site. Am J Epidemiol. 2013; 177(7): 625-637.

24. Perše M. Oxidative stress in the pathogenesis of colorectal cancer: cause or consequence? Biomed Res Int. 2013; 2013: 725710. doi: $10.1155 / 2013 / 725710$.

25. Taylor DP, Burt RW, Williams MS, Haug PJ, Cannon-Albright LA. Population-based family history-specific risks for colorectal cancer: a constellation approach. Gastroenterology. 2010; 138(3): 877-85. 